Successful Knowledge Management Implementation in Global Software Companies

By: Nikhil Mehta

Mehta, N. (2008). Successful Knowledge Management Implementation in Global Software Companies, Journal of Knowledge Management, 12(2), 42-56.

Made available courtesy of Emerald Publishing: https://doi.org/10.1108/13673270810859505

(C) 2008 Emerald Group Publishing Limited. This work is licensed under a Creative Commons Attribution-NonCommercial-NoDerivatives 4.0 International License. To reuse this document for commercial purposes, permission should be sought by contacting permissions@emeraldinsight.com.

Abstract:

Purpose: The purpose of this paper is to develop and evaluate a concise framework to examine how global software companies with successful knowledge management (KM) programs create KM-enabled value. Design/methodology/approach: The framework was evaluated at three global software companies with successful KM programs. Data were generated based on 20 interviews with various individuals involved with the KM programs of three companies. Interviews were content analyzed by four coders who sorted the data into meaningful categories. Inter-coder agreement was significant. Findings: The paper provides evidence of various strategic, technological, and cultural issues influencing the success of KM programs in global software firms. Firms with successful KM programs typically develop three specific capabilities to address these issues. These capabilities, namely, Articulating the KM Strategic Intent, Facilitating the Knowledge Flows to Enable Innovation, and Assessing KM Value, when developed simultaneously, help firms create KM-enabled value. Research

limitations/implications: Interviews were limited to three companies in the software industry. Future interpretivist studies would benefit from a larger and more diverse sample. Practical implications: It is suggested that software firms develop specific capabilities to create KMenabled value. To provide clear benchmarks for developing these capabilities, a "KM implementation worksheet" is provided. Originality/value: KM-enabled value creation is discussed from a unique perspective developed by integrating literature on knowledge-based view and knowledge management. The paper conducts initial evaluation of the new perspective and provides a roadmap for future research endeavors. Also provided is practical help in the form of a worksheet for practitioners.

Keywords: Knowledge management | Interviews | Companies

Article:

Introduction 
Global software companies possess diverse knowledge resources to develop complex software solutions (Malhotra and Majchrzak, 2004). These resources, such as know-how, skills, and abilities, are located in specialized pockets distributed geographically and temporally (Alavi and Leidner, 2001). Software companies operating across global locations need to integrate their distributed knowledge resources to develop timely and workable solutions (Tiwana, 2003).

Another challenge for global software companies is to create new knowledge. Software engineering is a rapidly evolving field (Rus and Lindvall, 2002), and companies have to continually adopt new technologies and practices. New knowledge is required to support this adoption (Mathiassen and Pourkomeylian, 2003). Additionally, with software applications finding new uses in diverse markets, companies need to develop new knowledge in various functional domains. Thus, there is an increasing realization among the software firms that as global software market changes, new technologies proliferate, and competitors multiply, managing their knowledge resources will develop competitive advantage (Conner and Prahalad, 1996; Prusak, 1996).

To face these challenges, software companies invest millions of dollars in their knowledge management (KM) programs. But, despite compounded increase in KM dollars spent, executives in these companies still face considerable difficulties in their KM efforts (Garvin, 1993). Theoretically, the objective of their KM programs is to better manage their existing knowledge resources and to develop new ones, but practically that is easier said than done, which brings us to the objective of this paper: Successful implementation of a KM program remains an elusive goal for many global software companies, and deserves deeper analysis. Specifically, this study focuses on following question: How do global software companies with successful KM programs manage their existing knowledge resources, and simultaneously develop new ones to create value?

To find a possible answer, a three-staged KM implementation framework was developed. The framework, rooted in the theoretical streams of knowledge-based view (KBV) and knowledge management, was then evaluated by conducting in-depth case studies on successful KM programs of three global software companies. Our analyses provided initial support for the threestaged KM implementation framework, which the author discusses as the KM-enabled value creation cycle (VCC). The VCC framework represents a set of three capabilities that global software companies need to develop sequentially for successful KM implementation. These capabilities - Articulating the KM Strategic Intent; Facilitating Knowledge Flows to Enable Innovation; and Assessing KM Value help software companies:

- define the strategic intent of their KM program;

- initiate appropriate processes supported by organizational and individual facilitators; and - assess KM-enabled value thus created.

The rest of the paper is organized as follows. In the next section, the author discusses the knowledge-based view to develop the capabilities perspective underlying the VCC framework. The VCC conceptual framework is then developed from pertinent literatures in knowledge management. In the next section, an overview of research methodology is provided, and the VCC framework is evaluated. In the last section, a "do-it-yourself” KM implementation 
worksheet is provided to help managers in global software firms struggling with implementationrelated issues.

\section{Theoretical foundations}

Knowledge-based view

Recent perspectives on organizations have developed theoretical infrastructure to study competitive implications of knowledge. Knowledge-based view (KBV) is one such effort. Challenging the pure contractual interpretation of classical economic theories of firm, KBV defines the firm as a heterogeneous, knowledge-bearing entity that ideally manages its knowledge resources to create economic, social, intellectual, and cultural value (Prusak, 1996).

KBV evolved over the past 20 years by contributions from two streams of research. The first stream of research, characterized by Nelson and Winter's (1982, p. 14) evolutionary theory of the firm, identifies knowledge as "the genetic material of firms", and defines the firms' raison d'être as to provide a context for the interaction of this knowledge with the economic reality of the markets. Firms that provide better context for knowledge-market interactions are able to convert their knowledge resources into economically useful products and services. Teece (1998, p. 75) expanded this perspective by proposing that firms' knowledge resources underlie their products and services. Firms with better ability to create, transfer, and exploit their knowledge resources offer better products and services to the market.

Kogut and Zander's (1993) landmark study characterizes the second stream of KBV research. They proposed that firms' combinative capabilities help them exploit their existing knowledge resources and create new ones. Extending these ideas, Grant (1996a, 1996b) advocated the role of knowledge integration as an organizational capability.

This study combines the two streams of KBV literature to define the capabilities perspective underlying the VCC framework: global software firms with successful KM programs realize that knowledge resources underlie their products and services, and develop specific capabilities to constantly reconfigure their existing knowledge resources and to create new ones (Spender and Grant, 1995; Spender, 1996; Teece, 1998).

In light of the capabilities perspective, pertinent literature in knowledge management is discussed to identify specific capabilities that global software firms need to develop for successful KM implementation.

Knowledge management

KM literature in the last decade has shaped two perspectives of the field - taxonomic and process (Orlikowski, 2002; Hansen and Haas, 2001). The author discusses relevant studies in each of these perspectives to develop normative prescriptions for successful KM implementation.

Taxonomic perspective. Taxonomists have proposed various classifications of organizational knowledge. Nonaka (1994), for example, augmented Polanyi's (1967) classical distinction 
between tacit and explicit dimensions of knowledge to interpret tacit knowledge as unarticulated, rooted in experience, and highly contextual, and explicit knowledge as more precise and formally articulated but less contextual than the tacit one. Spender (1996) extended Nonaka's ideas by including an individual/social dimension to identify four separate knowledge categories. He also proposed that firms require different strategies for managing different types of knowledge.

Extending Spender's idea of KM strategy, Zack (1999a, p. 133) proposed three knowledge types: core knowledge (minimum knowledge required to stay in business); advanced knowledge (which enables competitive viability); and innovative knowledge (which enables competitive advantage), and argued that comparing existing knowledge in these categories with firms' future knowledge requirements would highlight potential knowledge gaps, which should guide firm's KM strategy.

The taxonomic literature is prominent by its key idea that organizational knowledge exists in multiple flavors and, given this multitude, firms need a clear strategy to manage it. Based on this idea, the author proposes "Articulating the KM Strategic Intent" as the first capability that firms need to develop to successfully implement a KM program. To develop the Articulating capability, firms need to define their KM strategic intent, which is a compelling vision statement for their KM program (Sher and Lee, 2004; Zack, 1999a). An Ernst \& Young's study of 431 USA and European organizations identified "absence of a clear KM strategy" among the top three most critical impediments to successful KM implementation (Ruggles, 1998). Developing the Articulating capability addresses this issue. Another advantage of developing the Articulating capability is that by identifying specific KM objectives, it prevents firms from mistaking the KM program as a panacea for all its problems.

A realistic method of defining the KM strategic intent is to identify the "strategic knowledge gaps", which represent the disparity between firms' existing knowledge resources and the knowledge resources required by firms to successfully exploit future opportunities (Zack, 1999a). Once the strategic knowledge gaps are uncovered, firms can fill these gaps by reconfiguring their existing knowledge resources, and by creating new ones. Thus, a developed Articulating capability would connote that firms have a clear KM strategic intent that identifies their strategic knowledge gaps.

Process perspective. The process perspective of KM literature focuses on organizational knowledge flows. Research in this stream identifies a dynamic set of activities, called KM processes, which improve firm's knowledge flows. Conceptual studies in process-based literature discuss four generic KM processes: knowledge storage, knowledge transfer, knowledge application, and knowledge creation (Alavi, 2000). Knowledge storage involves converting firms' knowledge resources into knowledge units, which are "formally defined, atomic packets of knowledge content that can be labeled, indexed, stored, retrieved, and manipulated" (Zack, 1999 b, p. 48), and storing these units in a usable format. Knowledge transfer, application, and creation entail moving these units across the length and breadth of the organization to facilitate their application, and to create new knowledge. 
Recent process-based studies have discussed the importance of various infrastructures that firms need to support KM processes (Alavi and Leidner, 2001; Gold et al., 2001; Lee and Choi, 2003). Firms that initiate KM processes supported by appropriate infrastructures improve creativity, innovativeness, and financial performance (Soo et al., 2002).

Extending these ideas, the author proposes "Facilitating Knowledge Flows to Enable Innovation" as the second VCC capability that firms need to develop. Developing the Facilitating capability entails initiating appropriate KM processes to improve knowledge flows, and introducing appropriate organizational and individual facilitators to support these processes.

Organizational facilitators are introduced by developing:

- the human infrastructure, i.e. assigning clear roles and responsibilities for KM implementation; and

- the technological infrastructure to support knowledge storage, transfer, and application.

Human infrastructure: KM programs usually involve cross-functional processes, and traditional organizational roles are unable to manage such scope. The Ernst \& Young study reported "establishing KM roles to collectively own the responsibilities of the program" as the third most important requirement of successful KM implementation (Ruggles, 1998). To develop human infrastructure for their KM program, global software firms typically gather a central knowledge team. KM roles (such as knowledge champions) are also created within each business unit to coordinate the unit's KM activities with the central team (Prusak, 1998).

Technological infrastructure: technological infrastructure primarily includes various technical applications supported by information technologies. Applications can be categorized as integrative and interactive (Zack, 1999b). Integrative applications such as document repositories enable explicit knowledge exchange. They enable knowledge capture and its storage as useable knowledge units. At the users' end, integrative applications facilitate the search for appropriate knowledge units and help present them meaningfully across multiple contexts of use.

Interactive applications create opportunities for tacit knowledge exchange. Collaborative and distributed learning applications (like discussion forums, Lotus Notes, and multimedia based applications like videoconferencing) help people within the organization surmount structural and geographical obstacles to knowledge sharing.

Software firms with successful KM programs also introduce individual facilitators along with organizational facilitators. Individual facilitators help develop a KM supportive culture in the organization. As per the Ernst \& Young study, 57 percent of respondents identified nonsupportive organizational culture as the biggest impediment to employee participation in the KM program. Hlupic et al. (2002, p. 97) also described a management trap when "KM, dominated by management initiatives, is unlikely to be effective unless knowledge workers willingly participate in it". Managers can address this issue by introducing individual facilitators, which improve employee attitude towards the KM program, thereby improving their knowledge usage patterns (Hauschild et al., 2001). To introduce individual facilitators, firms first need to assess their employees' knowledge usage patterns, followed by: 
- Creating an environment that increases employees' yearning for more and better knowledge inputs in their everyday activities. This can be achieved by: establishing clear and ambitious knowledge usage objectives (e.g., setting high quality standards for software development) to elicit the "knowledge pull" behavior from employees; and then rewarding the "knowledge pull" behavior to ensure its repetition.

- Improving knowledge search behaviors of employees, thus helping them find relevant knowledge inputs.

Software firms that successfully introduce organizational and individual facilitators to support $\mathrm{KM}$ processes typically improve employee participation in the KM program. This helps software firms better utilize their existing knowledge resources and simultaneously create new ones, thus filling their strategic knowledge gaps (Sher and Lee, 2004). This begets internal as well as external innovation (Purvis et al., 2001; Demsetz, 1991; Spender, 1996). Software firms incorporate internal innovations (e.g., process improvements) to create internal value, and communicate and deliver external innovations (e.g., better products and services) to the market to create external value (Davenport and Prusak, 1998; Kogut and Zander, 1993; Szulanski, 2001). Value thus created can be (Miles et al., 1998):

- economic, such as cost savings from innovative processes (internal); higher profits from improved products and services (external);

- social value, created in the form of tightly coupled networks with business partners (with suppliers, for example);

- intellectual value, which includes better appreciation of the projects, brands, patents, and trade secrets; and

- cultural value, for example by improving firm's human focus.

Both internal as well as external value need to be assessed, and successful knowledge-managing firms develop the fourth VCC capability - Assessing KM Value to do that. Building the Assessing capability involves developing direct as well as indirect measures of value assessment. Both measures are appropriate for assessing economic value, while indirect measures are better suited to assess alternative forms of value (e.g., social value, intellectual value, and cultural value). Firms with a developed Assessing capability possess robust direct and indirect measures to assess economic, social, intellectual, and cultural value created internally as well as externally.

VCC conceptual framework

Figure 1 presents the VCC framework with possible interdependencies between the three capabilities - Articulating the KM Strategic Intent, Facilitating Knowledge Flows to Enable Innovation, and Assessing KM Value. The feed-forward and feedback arrows intertwine these capabilities into a logical framework, which is summarized below. 


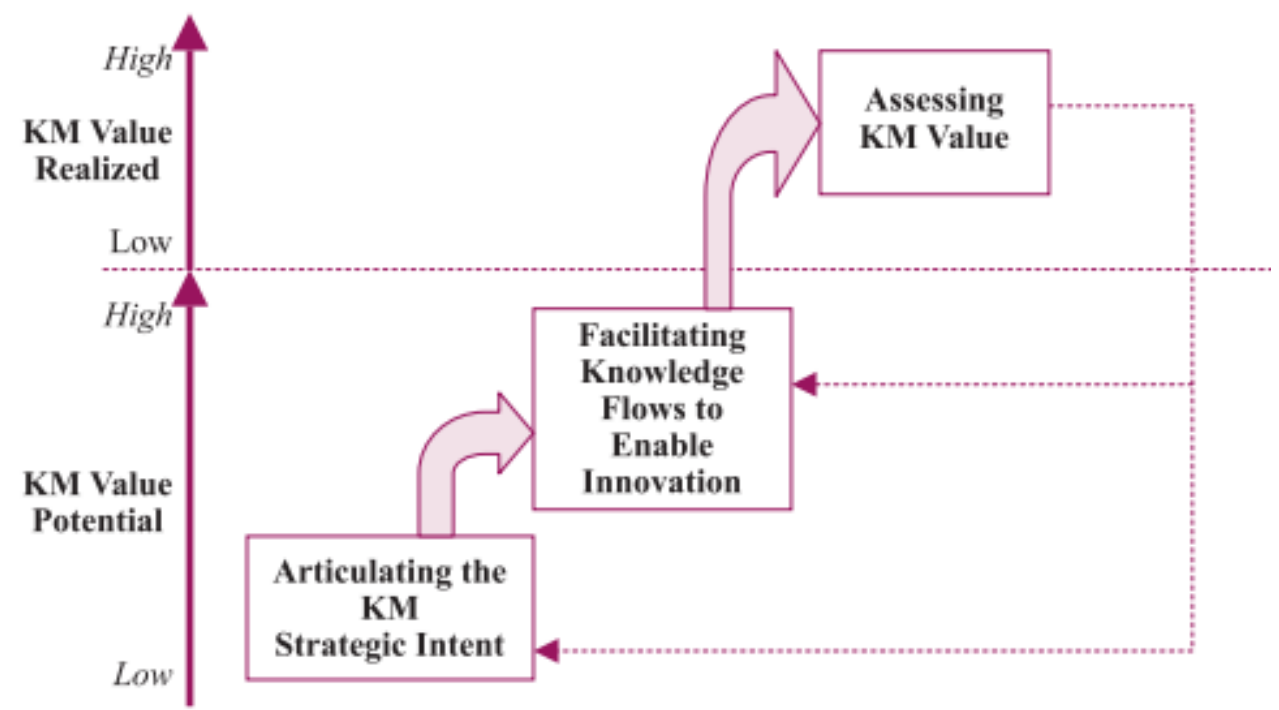

Figure 1. KM-enabled value creation cycle

The Articulating capability helps software firms identify their strategic knowledge gaps, which reflects the divide between firms' existing knowledge resources and their future knowledge requirements. The objective of KM programs is to fill these gaps. To fill these gaps, the Facilitating capability improves organizational knowledge flows by initiating KM processes supported by appropriate organizational and individual facilitators. Improves knowledge flows lead to better utilization of existing knowledge resources and creation of new ones, thus filling the strategic knowledge gaps and helping firms innovate. Incorporating internal innovations creates internal value, while external innovations are delivered to market for external value. The Assessing capability helps evaluate both internal and external value.

The light dotted arrows in the VCC framework represent the feedback communication processes that carry insights gathered via the Assessing capability. These processes play a critical role in the future modification of VCC capabilities, and are well researched as organizational learning in various books (Nonaka and Takeuchi, 1995; Brown and Duguid, 2000) and special themed issues of Organization Science (1991) and California Management Review (1998). The VCC framework also includes the feed-forward arrows that illustrate various communication and delivery processes between adjacent constructs. They also establish the chronology for developing the three capabilities.

To summarize, the VCC framework proposes that global software firms implement successful KM programs by:

- developing the proposed capabilities and their related processes in an overlapping sequence, and continually modifying them to fill their strategic knowledge gaps, which stimulates innovations;

- incorporating internal innovations to create internal value, and communicating and delivering product and service-related innovations to the market, thus creating external value; and 
- using various feedback and feed-forward routines to reinforce the future iterations of this value-creating cycle.

\section{Research methodology}

A multiple case-based research was conducted to evaluate the VCC framework. KM programs of three global software companies were examined. The three companies had attained Level 5 of software engineering institute's capability maturity model (SEI-CMM). Company 1 had a market capitalization of $\$ 10$ billion and 2003-2004 profits of $\$ 270$ million. It employed over 35,000 people scattered over 30 offices and software development centers in 17 countries. Company 2 employed over 39,000 people at eight software development centers and 33 global locations. With 2003-2004 profits of over \$260 million and market capitalization of \$10.4 billion, it was world's first PCMM and CMMi Level 5 software company. Company 3 had a market capitalization of $\$ 2$ billion and 2003-2004 profits of $\$ 172$ million. It employed more than 16,300 people at 26 global locations.

The three companies had been implementing their KM programs over the past few years. Their KM programs had similar timelines. The KM program of company 1 was aimed at reducing software development costs. At Company 2, the KM objective was to improve the quality of software development processes, while at Company 3, the KM program was aimed at enabling virtual teamwork among globally distributed sales personnel.

KM implementation at these companies was examined. Successful KM implementation, characterized by KM-enabled value creation, was defined uniquely for each of the three programs in light of their respective objectives. At Company 1, KM-enabled value was defined as "the number of man-days saved per person in a project as a direct result of knowledge reuse". Company 2 identified its cost of quality metrics as indicators of KM-enabled value-creation, while Company 3 recognized "number of new projects landed" as its indicator of KM-enabled value creation, and thus, successful KM implementation.

The primary data for this study came from 20 semi-structured interviews. Table I consolidates a list of people interviewed in each firm. An interview guide was used in most interviews (see Appendix), and the average time per interview was about 50 minutes. Information from other sources (e.g., websites and project documents) was also accumulated to substantiate the primary data.

The notes taken during the interviews were then content analyzed. The first stage of content analysis involved unitizing the data. According to Krippendorff (1980), units are wholes that are distinguished and treated as independent elements. Units can be defined on the basis of categorical, thematic, syntactical, physical, and propositional distinctions. The author unitized the 20 interview transcripts into distinct meaningful units. Three doctoral students then independently examined these units and summarized them into fewer meaningful units (Holsti, 1968). These units were then used to identify specific themes. Inter-coder agreement was 85 percent over 265 elements coded by each coder. On comparing and discussing the themes identified by each coder, three broad categories emerged that coincided with the three VCC capabilities. In the second phase of analysis, three different doctoral students were recruited as 
independent coders to code the elements as per the three identified categories. Each coder was asked to assign the elements to appropriate category and inter-coder reliability was assessed. Overall inter-coder reliability was 0.72 , which is significant for qualitative studies. Kappas for the three categories were $0.78,0.77$, and 0.85 respectively. Results for each of the three categories are discussed below. Analyses revealed that these companies developed the three VCC capabilities to achieve their KM objectives.

Table I. People interviewed in each firm

\begin{tabular}{|l}
\hline Firm People interviewed \\
\hline 1 Chief Knowledge Officer (CKO) \\
KM Technical Head \\
KM Brand Manager \\
Associate Vice-President (Operations) and Program Manager (Software Engineering Process Group): \\
Responsible for developing core KM processes and synchronizing them with the core software engineering \\
processes \\
Three Business Managers: To get the users' perspective. Each of them headed three largest business \\
divisions, one of them was a strong critic of the KM program \\
Chief Operating Officer (COO): Envisaged the KM initiative \\
Chief Quality Officer (CQO): Also headed the KM initiative \\
Two Senior Quality Managers: Next in KM hierarchy \\
KM Technical Head \\
General Manager (Enterprise Services Division): to get users' perspective \\
General Manager (KM Initiative): Second in KM hierarchy after the chief quality officer (CQO) \\
Senior Quality Consultant: Third in KM hierarchy \\
Knowledge Manager: Fourth in KM hierarchy \\
Manager (Talent Engagement \& Development): The last in KM hierarchy \\
Two Systems Managers: To get the users' perspective
\end{tabular}

Category 1: Articulating the KM strategic intent

A key requirement for defining the strategic intent is the support of top management. At Company 1, the CEO initiated the KM program by constituting a KM committee consisting of himself, the chief operating officer (COO), and a newly appointed principal knowledge manager. At Company 2 and Company 3 also, the program was initiated at the behest of their senior managers. The KM efforts of these two companies were slow in initial stages, but gained momentum once these managers shared their KM vision with other members of the top management.

Once the KM steering committees were instituted at the three companies, their primary task was to identify strategic gaps, i.e. areas where company's existing knowledge resources were insufficient to exploit future business opportunities. For example, committees at Company 1 and Company 2 identified strategic gaps in their software development function, while Company 3 noticed that it needed to reinforce its pre-sales and sales functions. The respective KM committees then identified specific objectives for the KM program in light of their strategic knowledge gaps.

A key benefit of identifying specific KM objectives was that it provided the companies with preliminary parameters to assess if the objectives were being met. As discussed earlier, company 1 , identified "the number of man-days saved per person per year in a software project" as its assessment measure, and Company 2 utilized "cost of software quality metrics" (e.g., defect rate) 
as its assessment measures. Company 3 identified "number of new projects landed" as its assessment parameter.

Category 2: Facilitating knowledge flows to enable innovation

Once the KM strategic intent is defined, managers can initiate KM processes, supported by KM facilitators - both organizational and individual.

Organizational facilitators. Human infrastructure: KM strategies of the three companies addressed this requirement by recommending appropriate $\mathrm{KM}$ architectures that would suit the requirements of each company, as well as the global software industry. For example, Companies 1 and 2 adopted a decentralized architecture that distributed the KM responsibilities across the organization. Employees and top management shared responsibility to create knowledge, while the responsibility to transfer knowledge was entrusted to a centralized KM team in each of the companies. These team, headed either by the chief quality officer or a newly appointed chief knowledge officer, typically had four sub-groups:

1. a content management group that handled issues related to content appropriateness, information confidentiality, and knowledge codification;

2. evangelists to conduct events and programs to ensure the top of the mind recall of the KM program;

3. a technology group that developed and maintained the technical infrastructure; and

4. a process expert group to identify the KM processes and to synchronize them with core business processes.

The companies also created KM roles within each business unit to coordinate the KM activities within that unit. For example, Companies 1 and 3 appointed, "knowledge primes" within each business unit. Company 2 called them "knowledge champions".

A decentralized KM architecture helped these companies create a parsimonious and flexible KM program that was responsive to their future demands. This approach also accrued other benefits. Assigning separate KM responsibilities to the top management, the KM team, and the employees avoided confusion and enhanced accountability. It also improved employee participation by instilling in them a sense of commitment towards the program.

Company 3 initially adopted a centralized KM architecture to enable a clear enterprise view of the knowledge needs of its employees. However, because of the knowledge intensive nature of the software industry, the centralized approach resulted in creation of dysfunctional ossified knowledge structures after some time, and the company had to adopt the decentralized architecture.

Technological infrastructure: as discussed earlier, a robust technological infrastructure includes both integrative and interactive KM applications. The technological infrastructure at the three companies typically included a KM system. The system had a portal front-end linked to the corporate intranet. An electronic document repository and various technical discussion forums were attached to the back-end of the KM portal. Certain applications were inter-related, for 
example, completed discussions threads from the discussion forums were also saved in the document repository for later retrieval. Companies 1 and 3 also added expert yellow pages to facilitate tacit knowledge exchange. Software-related issues could be discussed with experts at any of the global locations with the help of videoconferencing facilities.

With the development of human and technological infrastructures, knowledge creation, storage, and transfer were facilitated. For example in the three companies, top management's commitment to the KM program led to the creation of new knowledge-creation units. Also, the content management group within the respective KM teams converted new knowledge into "knowledge units" and made them available through the KM system.

The human and technological infrastructures also facilitated tacit knowledge sharing. The knowledge champions at Companies 1 and 2, and the knowledge primes at Company 3, played a significant role in enabling tacit knowledge exchange. They organized KM seminars and lectures by technical and functional experts from other units. They also conducted knowledge transfer (KT) sessions within their units, where representatives from various projects met in person, or through videoconferencing, to discuss their projects' knowledge requirements. Tacit knowledge sharing was also facilitated by the KM system (e.g., through expert yellow pages and discussion forum).

Individual facilitators. Assessing employees' knowledge usage patterns: at Company 1 and Company 2, internal surveys, backed by one-on-one interviews, were undertaken to understand the employees' knowledge usage patterns, especially the usage of knowledge relevant to the strategic knowledge gaps. One such learning at Company 1 was that the newly recruited software engineers were more open towards obtaining and using new knowledge as compared to the more experienced engineers. A better understanding of such behavior patterns helped managers at Company 1 design strategies to improve employees' desire for knowledge.

Improving employees' desire for knowledge: Company 1 and Company 2 accomplished this by:

- $\quad$ setting global standards for their software development processes; and

- recognizing the employees who actively participated in the KM program to achieve those standards.

Improving employees' knowledge search behaviors: the three companies helped their employees improve their knowledge search behaviors by:

- making them aware of new knowledge sources made available by the KM program; and

- convincing them of the benefits of using these sources over and above their existing ones.

For example, to improve employees' aware of the KM system, the KM teams at these companies organized company-wide presentations about the KM portal and various applications attached to it. Additionally, early users of the KM system were attracted by a regular display of stock information and soccer scores on the portal. Company 1 buttressed these activities by rewarding "knowledge currency points" to the frequent contributors to the KM system. Employees could exchange these points for products from an e-commerce company. 
Early benefits of using the KM system were assessed regularly from the system's more active users. These benefits were then communicated to both the active users to improve their conviction towards the KM system, and the less active user groups to incite them to use the system. For example, to involve the more experienced software developers, the KM teams projected benefits of using the KM system - such as the wealth of information they would receive within half-hour of posting a technical query on an online bulletin board. This motivated them to not only use the system but also to reciprocate the knowledge-sharing behavior, thus contributing to the success of KM program.

Category 3: Assessing KM-enabled value

The three companies had developed a set of direct as well as indirect value-assessment measures. Direct measures were aimed at assessing the creation of conventional value. Company 1 had focused its KM program on reducing software development costs. To assess KM enabled value, Company 1 compared its software projects that actively used the KM system, to the ones that did not use it at all. The projects using KM system reported saving about 4 man-days per person as a direct result of reusing project-related knowledge available from the KM system. Company 2, which had focused its KM program on improving the quality of their software development process, examined the quality metrics of high knowledge-sharing projects. The defect rate in these projects was 15 percent less than the organizational average. Their overall cost of quality was also about 13 percent lower than the organizational average. Company 3, which had aimed at "enabling virtual teamwork among the globally distributed sales personnel", noted that sales managers who actively participated in the KM program prepared competitive proposals by receiving valuable and timely inputs from their colleagues around the world, thereby winning more projects.

Indirect measures assess the creation of alternative forms of value such as intellectual capital, brand recognition, and client satisfaction. Company 1 had won the Global Most Admired Knowledge Enterprise (MAKE) award in 2003 and 2004, and Company 2 had won KMWorld's KM Reality award for 2002 in recognition of its KM practices.

\section{Research implications and future opportunities}

This study discusses and tests the underlying logic of KM-enabled value creation in global software firms in terms of specific capabilities firms need to develop. In doing that, this study provides a foundation for future research aimed at measuring KM success.

Additionally, the discussion of VCC framework integrates two key theoretical streams knowledge-based view and knowledge management. Integrating these streams provides opportunities for future interdisciplinary research, especially in developing the KM theory. Future studies can utilize the VCC framework to develop broad research propositions. A brief discussion regarding how to develop the propositions is provided below.

The VCC framework proposes that KM-enabled value creation depends on the level to which the Articulating, Facilitating, and Assessing capabilities are developed. These capabilities can 
typically be undeveloped or developed (Grant, 1996a). Table II displays possible interrelationships among these two development levels. The underlying assumption guiding these inter-relationships is that outputs from the antecedent capability have implications for the development of the subsequent capability. A reference label is added to illustrate the firms belonging to each of these system states. A caveat regarding the labels though, they merely refer to the KM value-creating capability of a firm. For example (see Table II), for firms in the "Interested" category, the Articulating capability is developed, but the Facilitating capability is either undeveloped or developed. In the former case, the Enabling capability is typically undeveloped, while in the latter case, it can be either undeveloped or developed.

Research propositions can be developed from Table II. One such proposition is developed as an illustration.

Table II. Theoretical predictions and reference labels for firms

\begin{tabular}{|lllll|}
\hline Articulating & Capabilities & & & \\
\hline Fndeveloped & Eacilitating & Assessing & Value created & Label \\
Developed & Undeveloped & Undeveloped & None & Inefficient \\
& Developed & Undeveloped & None & Interested \\
& & Undeveloped & Low - Moderate & Intelligent \\
& & Developed & High & Innovative \\
\hline
\end{tabular}

\section{Proposition}

Firms with developed Articulating and Facilitating capabilities, but undeveloped Assessing capability will create low KM-enabled value.

The proposition suggests that given fully developed Articulating and Facilitating capabilities, a software firm's ability to create value will be constrained by yet undeveloped Assessing capability. Once such propositions are developed, future research can then develop testable hypotheses to conduct a more detailed empirical investigation of the VCC framework. For example, a small subset (related to the Facilitating capability) of the above proposition can be utilized to formulate the following hypothesis:

Sample hypothesis

Efforts to improve employees' knowledge search behaviors will be more fruitful when a firm has extensive IT-based KM applications.

\section{Managerial implications: the KM implementation worksheet}

How can global software firms utilize the VCC framework? The underlying logic of VCC framework is that the extent to which a software company develops the three VCC capabilities influences its ability to create KM-enabled value. This proposition is illustrated in a KM implementation worksheet for managers (see Figure 2), which includes three VCC capabilities (the white boxes on the top), possible levels of these activities, and KM-enabled value created (the blue column). 


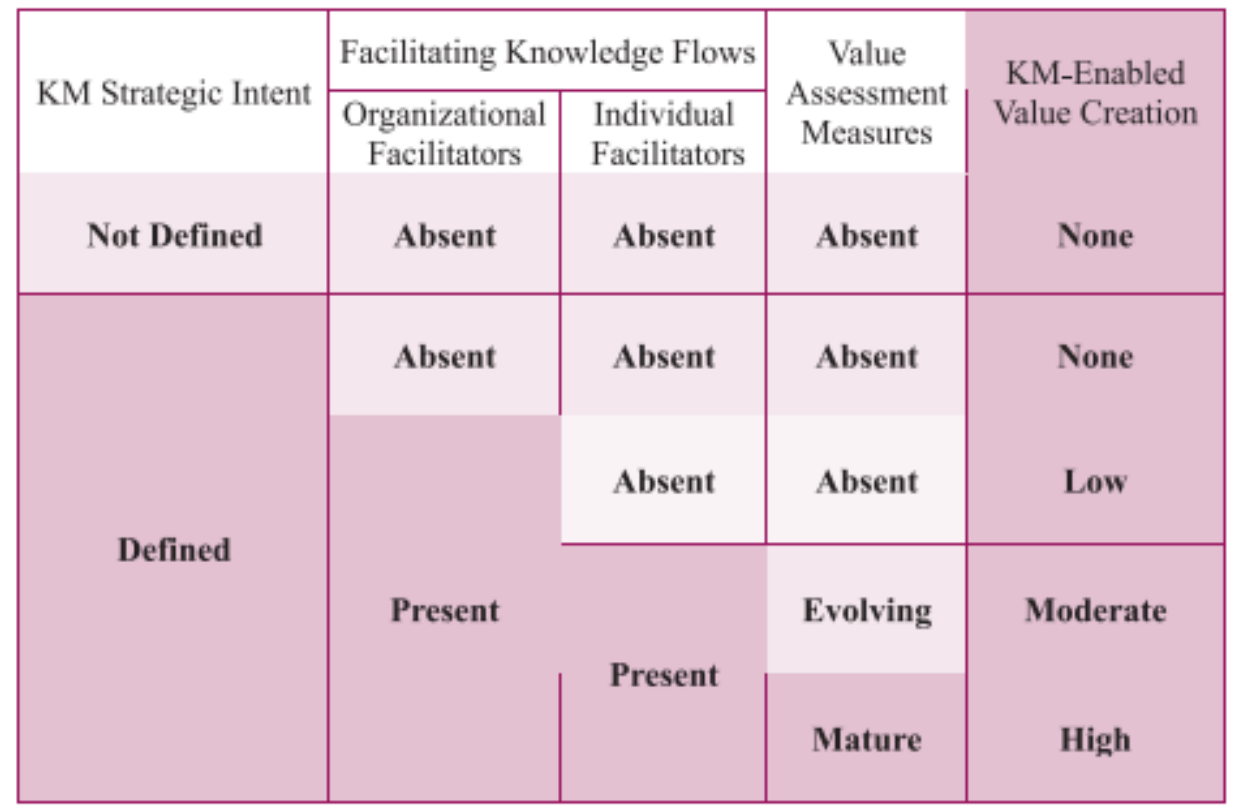

Figure 2. KM implementation worksheet

The worksheet is based on following logical assumptions:

- The KM Strategic Intent can be either "Defined" or "Undefined". Undefined strategic intent connotes that the company has not identified its "strategic gaps". Thus the firms cannot develop subsequent capabilities. Such firms fail to create KM-enabled value. If the intent is defined, but the firms haven't yet developed subsequent capabilities, they will still not create KM-enabled value.

- With the strategic intent defined and the organizational facilitators in place, firms may, at best, create low levels of KM-enabled value, as the individual facilitators are still absent.

- With the introduction of individual facilitators, value-creation will improve, but will remain at moderate levels, as the value-assessment measures are still evolving, and the firms are unable to effectively assess whether the strategic knowledge gaps have been filled.

- Once the value-assessment measures have matured, firms are able to gather valuable feedback, and use it to modify the three capabilities.

Managers can use a blank worksheet and fill the colored cells with appropriate level of KM activities as they carry them out. At any point of time, the worksheet will thus display the status of firms' KM program. This will improve firms' ability to diagnose and isolate probable reasons, if any, for low levels of KM value creation. In addition, the worksheet will also ensure that all managers involved in the KM program share the same perspective.

\section{Conclusion}

It is now possible to answer the question raised in the beginning of this paper: How do global software companies with successful KM programs manage their existing knowledge resources, and simultaneously develop new ones to create value? Successful KM programs at global 
software companies are influenced by various strategic, procedural, technological, and cultural issues. Firms develop three specific capabilities to address these issues. The capabilities, when developed simultaneously, help software firms create KM-enabled value. Firms can utilize the $\mathrm{KM}$ worksheet provided in this paper to establish clear benchmarks for developing each capability, and of the resulting value creation.

\section{References}

Alavi, M. (2000), "Managing organizational knowledge", in Zmud, R.W. (Ed.), Framing the Domains of IT Management: Projecting the Future through the Past, Pinnaflex Educational Resources Inc., Cincinnati, OH, pp. 15-29.

Alavi, M. and Leidner, D. (2001), "Knowledge management and knowledge management systems: conceptual foundations and research issues", MIS Quarterly, Vol. 25 No. 1, pp. 107-36.

Brown, J.S. and Duguid, P. (2000), The Social Life of Information, Harvard Business School Press, Boston, MA.

Conner, K.R. and Prahalad, C.K. (1996), “A resource-based theory of the firm: knowledge versus opportunism”, Organization Science, Vol. 7 No. 5, pp. 477-501.

Davenport, T.H. and Prusak, L. (1998), Working Knowledge, Harvard Business School Press, Cambridge, MA.

Demsetz, H. (1991), "The theory of the firm revisited", in Williamson, O.E. and Winter, S.G. (Eds), The Nature of the Firm, Oxford University Press, New York, NY, pp. 159-78.

Garvin, D.A. (1993), “Building a learning organization”, Harvard Business Review, pp. 78-91.

Gold, A.H., Malhotra, A. and Segars, A.H. (2001), "Knowledge management: an organizational capabilities perspective”, Journal of Management Information Systems, Vol. 18 No. 1, pp. 185214.

Grant, R.M. (1996a), "Prospering in dynamically competitive environments: organizational capability as knowledge integration", Organizational Science, Vol. 7 No. 4, pp. 375-87.

Grant, R.M. (1996b), "Toward a knowledge-based theory of the firm”, Strategic Management Journal, Vol. 17, pp. 109-22.

Hansen, M.T. and Haas, M.R. (2001), "Different knowledge, different benefits: toward a productivity perspective on knowledge sharing in organizations", Academy of Management Proceedings.

Hauschild, S., Licht, T. and Stein, W. (2001), "Creating a knowledge culture", The McKinsey Quarterly, Vol. 1, pp. 74-81. 
Hlupic, V., Pouloudi, A. and Rzevski, G. (2002), "Towards an integrative approach to knowledge management: 'hard', 'soft' and 'abstract' issues", Knowledge and Process Management, Vol. 9 No. 2, pp. 90-102.

Holsti, O.R. (1968), "Content analysis", in Lindzey, G. and Aronson, E. (Eds), Handbook of Social Psychology, Vol. 2, Addison Wesley, Reading, MA, p. MA.

Kogut, B. and Zander, U. (1993), "Knowledge of the firm and the evolutionary theory of the multinational corporation", Journal of International Business Studies, Vol. 24 No. 4, pp. 625-45.

Krippendorff, K. (1980), Content Analysis: An Introduction to Its Methodology, Sage, Newbury Park, CA.

Lee, H. and Choi, B. (2003), "Knowledge management enablers, processes, and organizational performance: an integrative view and empirical examination", Journal of Management Information Systems., Vol. 20 No. 1, pp. 179-228.

Malhotra, A. and Majchrzak, A. (2004), "Enabling knowledge creation in far-flung teams: best practices for IT support and knowledge sharing", Journal of Knowledge Management, Vol. 8 No. 4, pp. $75-88$.

Mathiassen, L. and Pourkomeylian, P. (2003), "Managing knowledge in a software organization", Journal of Knowledge Management, Vol. 7 No. 2, pp. 63-80.

Miles, G., Miles, R.E., Perrone, V. and Edvinsson, L. (1998), "Some conceptual and research barriers to the utilization of knowledge", California Management Review, Vol. 40 No. 3, pp. 281-8.

Nelson, R.R. and Winter, S.G. (1982), An Evolutionary Theory of Economic Change, Belknap Press, Cambridge, MA.

Nonaka, I. (1994), “A dynamic theory of organizational knowledge creation", Organization Science, Vol. 5 No. 1, pp. 14-37.

Nonaka, I. and Takeuchi, H. (1995), The Knowledge Creating Company: How Japanese Companies Create the Dynamics of Innovation, Oxford University Press, New York, NY.

Orlikowski, W. (2002), "Knowing in practice: enacting a collective capability in distributed organizing", Organization Science, Vol. 13 No. 3, pp. 249-73.

Polanyi, M. (1967), The Tacit Dimension, Doubleday, New York, NY.

Prusak, L. (1996), “The knowledge advantage", Strategy and Leadership, Vol. 24 No. 2, pp. 6-8.

Prusak, L. (1998), “Why knowledge, why now?”, in Klein, D.A. (Ed.), The Strategic Management of Intellectual Capital, Butterworth-Heinemann, Boston, MA. 
Purvis, R.L., Sambamurthy, V. and Zmud, R.W. (2001), "The assimilation of knowledge platforms in organizations: an empirical investigation", Organization Sciences, Vol. 12 No. 2, pp. 117-35.

Rus, I. and Lindvall, M. (2002), "Knowledge management in software engineering", IEEE Software, May/June, pp. 26-38.

Ruggles, R. (1998), "The state of notion: knowledge management in practice", California Management Review, Vol. 40 No. 3, pp. 80-9.

Sher, P.J. and Lee, V.C. (2004), "Information technology as a facilitator for enhancing dynamic capabilities through knowledge management", Information \& Management, Vol. 41, pp. 933-45.

Soo, C., Devinney, T., Midgley, D. and Deering, A. (2002), "Knowledge management: philosophies, processes, and pitfalls", California Management Review, Vol. 44 No. 4, pp. 12950 .

Spender, J.C. (1996), "Making knowledge the basis of a dynamic theory of the firm", Strategic Management Journal, Vol. 17, pp. 45-62.

Spender, J.C. and Grant, R.M. (1995), "Knowledge and the firm: overview", Strategic Management Journal, Vol. 17, pp. 5-9.

Szulanski, G. (2001), "Knowledge creation: a source of value", Academy of Management Review, Vol. 26 No. 2, pp. 318-20.

Teece, D. (1998), "Capturing value from knowledge assets: the new economy, market for knowhow, and intangible assets", California Management Review, Vol. 40 No. 3, pp. 55-79.

Tiwana, A. (2003a), "Knowledge partitioning in outsourced software development: a field study", International Conference on Information Systems, Seattle, Washington, DC, pp. 259-70.

Zack, M.H. (1999a), "Developing a knowledge strategy", California Management Review, Vol. 41 No. 3, pp. 127-45.

Zack, M.H. (1999b), "Managing codified knowledge", California Management Review, Vol. 40 No. 4, pp. 45-58.

\section{Appendix. A partial list of open-ended questions for:}

The KM heads of the three firms:

1. What are the key objectives of firm's KM initiative?

2. How important a constituent is the knowledge management strategy of firm's overall corporate strategy? 
3. Which knowledge management systems have been implemented in the firm?

4. Which of the two components - technological or human - did you find more critical to the success of a knowledge management initiative?

5. What steps has the firm taken to motivate the knowledge workers to share and to apply available knowledge?

6. Is there a specific knowledge management framework/model that the firm has adopted? If yes, could you share it with me? If no, then what is the blueprint for firm's overall knowledge management effort?

7. Did you make any structural changes in the organization to implement the knowledge management systems?

8. What criteria does the firm use to measure the performance of knowledge management efforts (market share or profitability), ability to control costs, repeat business with clients?

The technical heads in the KM team:

9. What kind of KM architecture have you adopted?

10. What are various KM technologies and applications?

The users:

11. How would you assess the commitment of top management to the KM initiative?

12. Any perceived benefits of the KM program in general, and KMS in particular?

The brand manager (Firm 1):

13. What are various efforts that you've adopted to popularize the KM initiative?

The associate vice-president (Operations) and program manager (Software Engineering Process Group (Firm 1):

14. How did you arrive at the decision of keeping some KM processes voluntary and while making outhers mandatory to the employees?

The senior quality managers and senior quality consultant (Firms 2 and 3):

15. How are you trying to integrate your Six Sigma projects with your KM initiative? 